\title{
Antenatal Obstetric Hospitalization: Risk Factors and Pregnancy Outcomes in the University of Calabar University Teaching Hospital, Calabar - A Retrospective Review
}

\author{
Ubong Bassey Akpan ${ }^{1 *}$, Chidinma Enweremadu ${ }^{1}$, Emmanuel Monjok², Thomas Agan ${ }^{1}$ \\ ${ }^{1}$ Department of Obstetrics and Gynaecology, University of Calabar, Calabar, Nigeria; ${ }^{2}$ Department of Community Medicine, \\ University of Calabar, Calabar, Nigeria
}

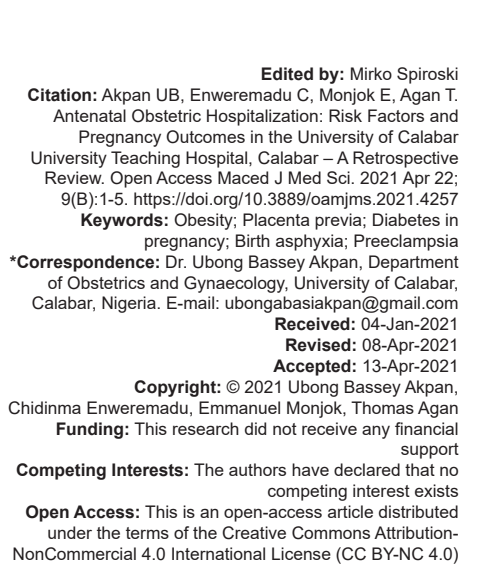

Abstract

BACKGROUND: Antenatal obstetrics hospitalization $(\mathrm{AOH})$ may be indicated due to pregnancy complications that need close surveillance and possible intervention.

AIM: The aim of this review was to assess the risk factors and the peripartum outcome of such women.

METHODS: Retrospective study of records of pregnant women was done. The risk factors of interest included materna demographic profile, obstetric factors, and medical comorbidities. Outcome of interest included discharge diagnoses, maternal death or morbidity, and perinatal outcome. Inferential statistics was used to assess significant relationship between variables. The level of significance was set at $p \leq 0.05$. Analysis was done using SPSS version 22.0.

RESULTS: The prevalence of $\mathrm{AOH}$ within the period under review was $2.8 \%$ among the 3686 women who delivered at UCTH. The mean maternal age was $29.24 \pm 4.059$ (SD) years. The mean body mass index (BMI) was $27.91 \mathrm{~kg} / \mathrm{m}^{2} \pm$ 3.704 (SD). The mean gestational age at admission was 33.03 weeks. The mean duration of hospitalization was 4.03 days. Seven $(7.7 \%)$ of them had chronic medical comorbidities. The case fatality rate for preeclampsia/eclampsia was low for $\mathrm{AOH}$ with (12.5\%) compared to $17.1 \%$ in none hospitalized women. The perinatal mortality rate was $66 / 1000$ live births. The duration of hospitalization was positively related to the maternal BMI ( $p=0.047)$. Booking status and duration of hospitalization did not significantly affect neonatal outcome/perinatal death $(p=0.905)$.

CONCLUSION: AOH may reduce incidence of maternal death However, long-term study may be indicated to assess the trend and neonatal/infant survival.

\section{Introduction}

Various health conditions may warrant hospital admission for in-patient care. Pregnancy and childbirth is among the most common indications for hospital admission in women globally [1], [2]. Several studies have shown about $8-27 \%$ of pregnant women may be hospitalized at least once before delivery in Europe and North America [3], [4].

Some chronic medical conditions like diabetes mellitus may necessitate pre-conception admission for control or during pregnancy. Furthermore, some systemic disorders may deteriorate due to the impact of pregnancy on maternal health with risk of indirect maternal death. Often time women are admitted to antenatal ward (ANW) when there is need for close surveillance and thorough evaluation to detect or prevent as well as manage any deterioration in maternal or fetal clinical state [5], [6].

However, decisions to admit women who present to hospital with complications during pregnancy may depend on several factors. Apart from the severity of the problem, other factors include gestational age, previous poor obstetric outcome, needs for review or intervention by other specialties, availability of medical expertise, need for surgical interventions, and for further investigations. Social and economic factors may also determine prevalence of admission to a tertiary facility: Availability of hospital beds, hospital services, proximity of services to the women's home, availability of home support, and patient's or doctors preferences [1].

A study comparing pregnant women who reported severe life threatening events showed that they were significantly more likely to be admitted to hospital during pregnancy [7]. Furthermore, hospitalization due to pre-existing medical conditions is an important indicator of maternal morbidity [3], [4].

Furthermore, available evidence have suggested that babies born in a tertiary hospital to women experiencing pregnancy complications (including intrauterine referrals from other hospital) have lower rates of morbidity and mortality than babies who were transferred after they were born [8], [9].

Most studies that have focused on outcome of high risk pregnancies did not assessed the influence of 
antenatal in-patient care on these outcomes, more so in Nigeria and other countries in sub-Saharan Africa.

Therefore, the aim of this study was to assess the indications and outcomes of pregnancies that were admitted for in-patient care and interventions during the antenatal period and also attempt to determine the impact of such care on the prognosis of various maternal and neonatal conditions.

\section{Materials and Methods}

The study was a retrospective research reviewing the cases that were admitted to the ANW of the UCTH from January 1, 2014 to December 31, 2015.

\section{Study population}

The study population comprised all pregnant women with gestational age 28 weeks and above who delivered in the UCTH during the period under review. The gestational age of fetal viability in Nigeria is 28 weeks. Viability in the context of obstetrics is defined by $50 \%$ fetal survival rate if the baby is born at that gestational age. It is much lower in developed countries due to availability of facilities for intensive neonatal care. Complications of pregnancies occurring before 28 weeks are usually managed in the gynecological clinics and wards.

\section{Sources of data}

The ANW admission register was used to search for the number of women who were hospitalized during the time frame. Their case notes were retrieved and analyzed. The delivery register was used to record the peripartum and neonatal outcomes. The total number of women who delivered during the period was noted. Furthermore, all the obstetrics complications were recorded and the prevalence was calculated. Women who defaulted or who did not deliver in UCTH were excluded in the analysis.

\section{Variables}

The risk factors of interest included maternal sociodemographic characteristics, obstetrics and medical factors, and paternal factors such as age and smoking. The outcomes of interest were duration of hospitalization, discharge diagnoses, mode of delivery, peripartum, and perinatal outcomes.

\section{Data management}

Indebt study of the case notes of the women with history of antenatal obstetrics hospitalization
$(\mathrm{AOH})$ who subsequently delivered in the hospital was carried out. Data were entered into SPSS version 22 and analyzed. Categorical variables were presented in simple proportion and percentages. Grafts or charts were used for clarity when necessary. Logistic regression was done to assess associations between independent and dependents variables. The level of significant was set at $p=0.05$.

\section{Results}

\section{Sociodemographic characteristics}

A total of 3686 pregnant women delivered at the hospital within the period of review. Out of this number, $103(2.8 \%)$ of them were admitted to antennal ward for in-patient care giving the prevalence of $\mathrm{AOH}$ of $2.8 \%$. Ninety-one completed case notes were available for analysis. Out of this number, $16(17.6 \%)$ of them did not receive any antenatal care (ANC) (unbooked) before hospitalization for obstetric emergencies.

A vast majority of them were literate and 51 (56\%) have attained tertiary level of education (Table 1). Eighty one (89.0\%) of them were married and majority of them were Christians and protestant/Pentecostal was the highest religious denomination recorded (51.6\%).

Table 1: Sociodemographic profile

\begin{tabular}{lll}
\hline Variable & Frequency & Percent \\
\hline Marital status & 2 & \\
Single & 81 & 2.2 \\
Married & 8 & 89.0 \\
Cohabiting & 91 & 8.8 \\
$\quad$ Total & & 100.0 \\
Highest level of education & 1 & \\
None & 3 & 1.1 \\
Primary & 35 & 3.3 \\
Secondary & 52 & 38.5 \\
Tertiary & 91 & 57.1 \\
Total & & 100.0 \\
Tribe/ethnic group & 10 & \\
Efik & 16 & 11.0 \\
Ejagham/Yakurr & 29 & 17.6 \\
Ibibio/Annang & 15 & 31.9 \\
Igbo & 2 & 16.5 \\
Yoruba & 1 & 2.2 \\
Hausa & 18 & 1.1 \\
Others & 91 & 19.8 \\
Total & & 100.0 \\
Religion & 21 & \\
Roman catholic & 18 & 23.1 \\
Orthodox & 47 & 19.8 \\
Protestants & 5 & 51.6 \\
Others & 91 & 5.5 \\
Total & & 100.0 \\
\hline
\end{tabular}

The mean maternal age was $29.24 \% \pm 4.059$ (SD) years and only two (2.2\%) were teenagers (less than 20 years of age). The mean paternal age was $35.74 \pm 3.343(\mathrm{SD})$ years. Only $7(7.7 \%)$ of the women took alcohol but none smoked or consumed tobacco in any form. The mean parity was 2.15 and 17 (18.7\%) were nulliparous while $3(3.3 \%)$ had delivered 5 or more children (grand multi-parity).

The mean body mass index (BMI) at booking or presentation was $27.9 \mathrm{~kg} / \mathrm{m}^{2} \pm 3.704$ (SD), there was 
high prevalence of overweight and mild obesity, BMI greater than $25.1 \mathrm{~kg} / \mathrm{m}^{2}$, in $76(83.5 \%)$ of the women reviewed (Table 2). However, the incidence of moderate to morbid obesity was low (BMI of $>35.1 \mathrm{~kg} / \mathrm{m}^{2}$ ) and this was recorded in 5 (5.5\%) of them.

Table 2: Demographic and obstetrics profile

\begin{tabular}{lll}
\hline Variables & Frequency & Percent \\
\hline Parity & 17 & \\
0 & 22 & 18.7 \\
1 & 23 & 24.2 \\
2 & 19 & 25.3 \\
3 & 7 & 20.9 \\
4 & 3 & 7.7 \\
5 and above & 2 & 3.3 \\
Age & 14 & 2.2 \\
$\leq 20$ & 42 & 15.4 \\
$21-25$ & 28 & 46.2 \\
$26-30$ & 5 & 30.8 \\
$31-35$ & 91 & 5.5 \\
$36-40$ & & 100.0 \\
Total & 15 & \\
BMI $\left(\mathrm{kg} / \mathrm{m}^{2}\right)$ & 50 & 16.5 \\
$18.51-25.00$ & 21 & 54.9 \\
$25.01-30.00$ & 5 & 23.1 \\
$30.01-35.00$ & 91 & 5.5 \\
$35.01-40.00$ & & 100.0 \\
Total & &
\end{tabular}

\section{Obstetrics conditions}

The mean gestational age at booking for ANC was 23.2 weeks, while the mean gestational age at admission to, ANW, was 33.03 weeks \pm 4.567 (SD). Table 3 shows that majority of them, 53 (58.2\%) had vaginal delivery while cesarean section rate was $41.8 \%$. The discharge diagnoses are also shown in Table 4. Seven $(7.7 \%)$ of the women had other co-medical condition which include sickle cell disease, asthma, and diabetes mellitus (Figure 1).

Table 3: Maternal discharge diagnosis

\begin{tabular}{lll}
\hline Valid & Frequency & Percent \\
\hline Normal labor & 53 & 58.2 \\
Previous C-section & 17 & 18.7 \\
Pre-eclampsia & 3 & 3.3 \\
Eclampsia & 5 & 5.5 \\
Placenta previa & 6 & 6.6 \\
Breech presentation & 6 & 6.6 \\
Malaria in pregnancy & 1 & 1.1 \\
Total & 91 & 100.0 \\
\hline
\end{tabular}

One maternal death was recorded. This was due to disseminated intravascular coagulation caused by severe preeclampsia. The various indications for caesarean sections are also shown in Table 3 . The duration of ANW admission ranged from 1 to 22 days. Average duration of hospital stay was 4.03 days. Re-admission to ANW was recorded in one woman (sickle cell patient).

\section{Neonatal/perinatal outcomes}

A total of 93 babies were delivered, 89 singletons and two set of twins. Fourteen neonates $(15.5 \%)$ delivered to these women were admitted to neonatal intensive care unit. The duration for neonatal admission ranged from 1 to 20 days. Birth asphyxia was the most common indication for neonatal admission, accounting for $43 \%$ of intensive care

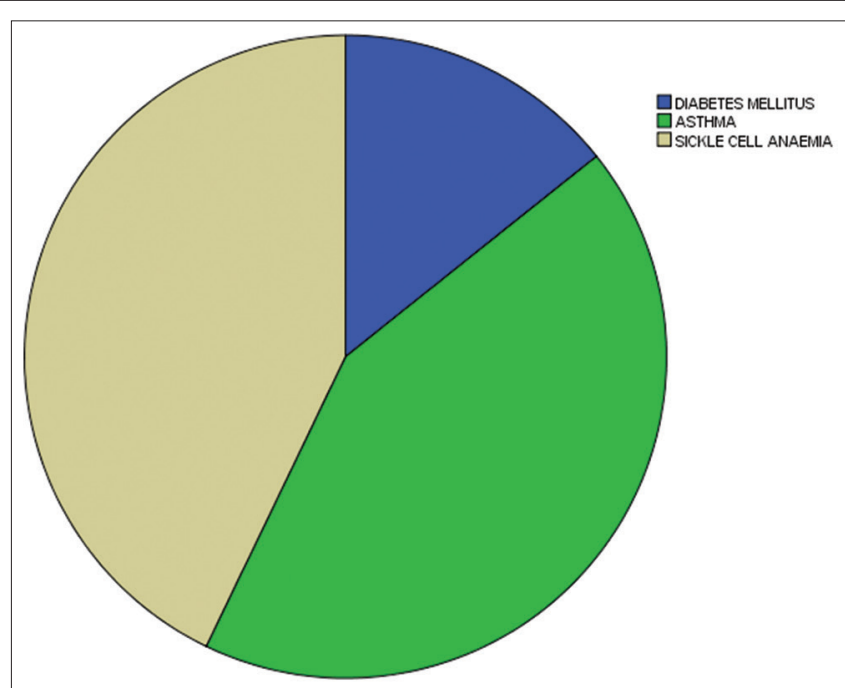

Figure 1: Medical comorbidities

unit admission. Two preterm births were recorded (Figure 2). The perinatal mortality rate was 66/1000 live births.

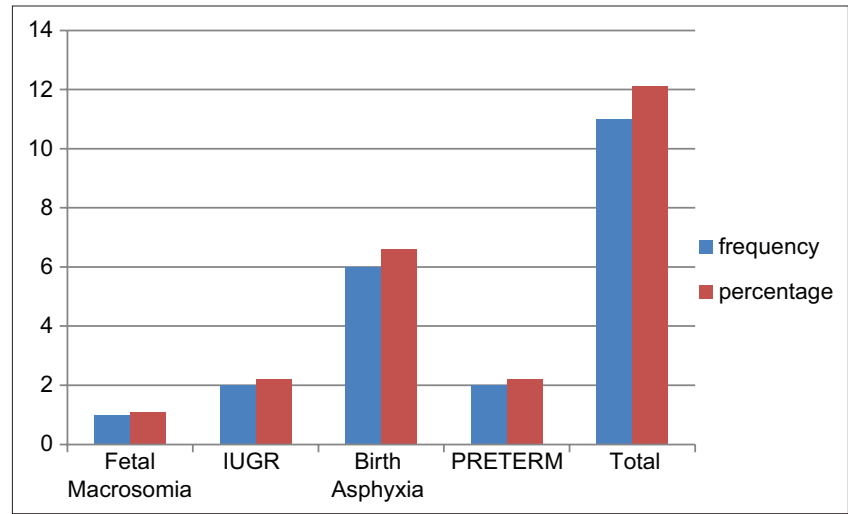

Figure 2: Neonatal discharge diagnosis

Birth asphyxia and low birth weights were the major causes of perinatal deaths. The gestational age at delivery did not significantly affect the Apgar score at $5 \mathrm{~min}(p=0.062)$. The booking status of the women on admission did not significantly influence perinatal outcome (IUCIR, IUFD, and birth asphyxia) $(p=0.905)$.

\section{Logistic regression}

Logistic regression analysis shows that the duration of antenatal hospitalization was significantly influenced by the maternal BMI ( $\left.p=0.047 r^{2}=0.044\right)$ while maternal age and parity did not significantly contribute to prolonged hospitalization ( $p=0.790$ and 0.180 , respectively).

Similarly, extreme maternal age did not accurately predict the neonatal complications ( $p=0.906)$. Furthermore, maternal education and age did not reliably predict poor obstetric outcomes $\left(p=0.606 ; \chi^{2}=4.527\right)$ and $\left(p=0.912 ; \chi^{2}=10.554\right)$, respectively. 


\section{Discussion}

This was a hospital based study as against population or community based studies in few publications on similar subjects in Denmark and Canada [5], [10]. In Nigeria, we do not have community based registers that include every pregnant woman in the community and her obstetrics profile. The only available records on such subjects are usually domiciled in health facilities where the women receive care during pregnancy and childbirth. The prevalence of antenatal hospitalization in this study was therefore based on the total number of women who received obstetric care in the tertiary hospital during the period of review.

Consequently the $\mathrm{AOH}$ prevalence of $2.8 \%$ in this study compared to $7.8 \%$ in a similar study in Denmark [10] was justifiable. Furthermore, as stated earlier, several social factors may influence a woman decision to utilize or present herself for hospital care in addition to the availability of bed spaces, nearness to facility, partner's support, her ability to recognize the danger signs and impending complication as well as the cost of care. In Nigeria, more than $70 \%$ of the population is not covered by health insurance. Health care expenses in most cases are usually out-of pocket expenses. In some cases, women default hospital admission against doctor's advice because the poor women may not afford admission fee.

Apart from maternal BMI, the other demographic features of the women did not predict adverse pregnancy outcome. High BMI was associated with prolonged hospitalization ( 2 weeks and more). As diabetes in pregnancy was among the common medical co morbidities, it is possible that many of them stayed longer in the hospital for control of blood glucose levels. Obesity is a known risk factor for diabetes in pregnancy. Thus, the reason that high BMI was associated with prolonged admission period. The incidence of preterm and low birth weight was low compared to other studies [5], [10]. Maternal smoking is rare in Nigeria. In fact in the study, no case was reported, and only a minute fraction indulged in moderate alcohol intake.

Advanced maternal age, cigarette smoking, educational level, and parity were identified factors for antenatal prolonged or recurrent hospital admission in a study in Europe [4].

The proportion of their neonates who were admitted to intensive care unit was $15.5 \%$ and far higher than the intensive care admission rate of about $6 \%$ in the general population of pregnant women in Calabar. The reason may likely be as a result of the perinatal complications from the high risk pregnancies that were hospitalized for closed monitoring.

However, the perinatal mortality rate of $66 / 1000$ live births recorded in this study was similar to that in the general population in Southern Nigeria (62.7/1000 live births) [11]. Even though these babies were born to mothers with life-threatening obstetric condition have increased risk of dying during the neonatal period, the expert care rendered by the specialist neonatology team in the tertiary hospital could have prevented many babies from dying.

Furthermore, only two cases of preterm births were reported, one due to preterm labor and another from a mother with preeclampsia. There was no case of extreme preterm birth (birth weight $<1 \mathrm{~kg}$ ).

The cutoff gestational age for fetal viability in our center is $\mathbf{2 8}$ weeks. Most countries in Europe and North America have fetal viability gestation ages of 20-22 weeks [10]. This could be the reason for decreased number of preterm birth in this study compared to studies in Europe and Canada since cases that occurred earlier than 28 weeks were not admitted to ANW.

The study also revealed a significant reduction in case fatality rate (12.5\%) from preeclampsia/eclamptic among $\mathrm{AOH}$ women compared to $17.1 \%$ among other non-hospitalized women who delivered in the hospital within the period under review. Globally, more than 50,000 maternal deaths are attributed to preeclampsia and other hypertensive disorders in pregnancy each year [12]. A significant proportion of such women died outside hospital without any care especially in Africa [12], [13], [14].

Cases of hypertensive disorders in pregnancy including preeclampsia among the women admitted for in-patient management during the antenatal period must have been properly evaluated and complications prevented or managed accordingly. For instance administration of antihypertensives and anticonvulsants (magnesium sulfate) while on admission might have prevented eclampsia and other life-threatening complication that could cause maternal deaths [12].

Among other conditions that could cause lifethreatening obstetric hemorrhage were major type placenta previa (type 3 and 4). Six cases were recorded among the $\mathrm{AOH}$ women and there was no maternal death reported in them. From the general record, 11 maternal deaths were attributed to obstetric hemorrhage among the non $\mathrm{AOH}$ women who delivered within the period. Most of them were unbooked and unprepared for such complications at the time of onset of symptoms.

The women who booked or presented early to the hospital must have been properly monitored for necessary maternal condition. They might have had ultrasound scan to determine the location of the placenta. Furthermore, blood and blood products might have been made available and reserved for them in case of severe obstetric hemorrhage.

As recognition of danger signs and complication readiness are low among the women in low income countries, hospital admission provides opportunity for health education, partner's involvement, and holistic care for individual patient. 


\section{Conclusion}

Antenatal hospitalization may improve maternal outcome of complicated pregnancies such as preeclampsia and major type placenta previa but may not necessarily influence perinatal outcome. Long-term studies are necessary to assess the trend vis-à-vis improve quality of care.

\section{References}

1. Australian Institute of Health and Welfare. Australian Hospital Statistics 2009-10, Canberra: AlHW, CAIW Cat No. HSE 107, Health Services; 2011.

2. Badgery-Parker $T$, Ford JB, Jenkins MG, Morris JM, Roberts CL. Patterns and outcomes of preterm hospital admissions during pregnancy in NSW, 2001-2008. Med J Aust. 2012;196(4):261-5. https://doi.org/10.5694/mja11.10717 PMid:22409693

3. Bacak SJ, Callagham WM. Dietz PM, Crouse C. Pregnancy associated hospitalization in the United States, 1999-2000. Am J Obstet Gynecol. 2005;192(2):592-7. PMid:15696008

4. Gazmararian JA, Peterson R, Jamieson DJ, Schild L, Admins MM, Desphance $A D$, et al. Hospitalization during pregnancy among managed care enrollees. Obstet Gynecol 2002;100(1):94$100 . \quad$ https://doi.org/10.1016/s0029-7844(02)02024-0 PMid:12100809

5. Liu S, Heaman M, Sauve R, Liston R, Reyes $F$, Bartholomew S, et al. An analysis of antenatal hospitalization in Canada, 1991-2003. Matern Child Health J. 2007;11(2):181-7. https://doi.org/10.1007/s10995-006-0154-3 PMid:17089198

6. Rastard B, Schei B. Factors predicting antenatal hospital admission in pregnancy. Scand J Prim Health Care.

\section{8;16:85-9.}

7. Rostard B, Schei B, Jacobsen G. Health consequences of severe lifeeventsforpregnancy.ScandJPrimHealth Care.1995;13(2):99$104 . \quad$ https://doi.org/10.3109/02813439508996744 PMid:7569486

8. Phibbs CS, Bronstein JM, Buxon E, Phibbs RH. The effects of patient volume and level of care at the hospital of birth on neonatal mortality. JAMA. 1996;276(13):10549. $\quad$ https://doi.org/10.1001/jama.1996.03540130052029 PMid:8847767

9. Sanderson M, Sappenfied WM, Jesperson KM, Liu Q, Baker AL. Association between level of delivery hospital and neonatal outcomes among South Carolina Medical recipients. AMJ Obstet Gynecol. 2000;183:1504-11. https://doi.org/10.1067/ mob.2000.107357

10. Bendix J, Hegaard HK, Langhoff-Roos J, Bergholt T. Changing prevalence and risk factors for antenatal obstetric hospitalization in Denmark 2003-2012. Clin Epidemiol 2016;8:1-22. Available from: https://www.dovepress.com/by197.210.29.222. [Last accessed on 2017 Aug 31]. https://doi.org/10.2147/clep. s102029

11. Ibekwe PC, Ugboma HU, Muoneke U. Perinatal mortality in Southern Nigeria: Less than half a decade to the millennium development goals. Ann Med Health Sci Res. 2011;1(7):215-22. PMid:23209977

12. Preeclampsia Foundation. Preeclampsia and Maternal Mortality: A Global Burden Updated May 01, 2013. Available from: http://www.preeclampsia.org/health.information/149advocacy-awareness. [Last accessed on 2018 Sep 07].

13. Kuklina EV, Ayala C, Callaghan WM. Hypertensive disorders and severe obstetric morbidity in the United States. Obstet Gynecol. 2009;113(6):1299-306. https://doi.org/10.1097/ aog.0b013e3181a45b25

PMid: 19461426

14. Bemett TA, Kotelchuck M, Cox CE, Tucker MJ, Nadeau DA. Pregnancy-associated hospitalizations in the United States in 1991 and 1992: A comprehensive view of maternal morbidity. Am J. Obstet Gynecol. 1998;178(2):346-54. https://doi.org/10.1016/ s0002-9378(98)80024-0

PMid:9500498 